CORRECTION

\title{
Correction: The m6A mRNA demethylase FTO in granulosa cells retards FOS-dependent ovarian aging
}

Zhong-xin Jiang (D), Yi-ning Wang, Zi-yuan Li, Zhi-hui Dai, Yi He, Kun Chu, Jia-yi Gu, Yi-Xuan Ji, Ning-xia Sun, Fu Yang and Wen Li

(c) The Author(s) 2021

Cell Death and Disease (2021)12:1114; https://doi.org/10.1038/s41419-021-04194-6

Correction to: Cell Death and Disease https://doi.org/10.1038/ s41419-021-04016-9, published online 27 July 2021

The original version of this article unfortunately contained a mistake. Due to a typesetting error the affiliations were incorrect. We apologize for the mistake. The correct affiliations are:

Zhong-xin Jiang1, 2, 3, †, Yi-ning Wang2, †, Zi-yuan Li2, †, Zhi-hui Dai4, †, Yi He2, Kun Chu2, Jia-yi Gu2, Yi-Xuan Ji2, Ning-xia Sun2,*, Fu Yang4,*, Wen Li1, 2,*

Affiliations:

1 Center for Reproductive Medicine and Fertility Preservation Program, International Peace Maternity and Child Health Hospital, School of Medicine, Shanghai Jiao Tong University, 200030 Shanghai, China

2 The Center of Reproductive Medicine, Shanghai Changzheng Hospital, Naval Medical University, 200003 Shanghai, China

3 Obstetrics and Gynecology Department, The 1st Naval hospital of Southern Theater Command, 4 The Department of Medical Genetics, Naval Medical University, 200433 Shanghai, China524005 Guangdong, China
${ }^{\dagger}$ These authors contributed equally.

* Corresponding author.

In addition, there was a misspelling in the footnote of Figure 1C: form should be changed to from. The original article has been corrected.

\begin{abstract}
(i) Open Access This article is licensed under a Creative Commons Attribution 4.0 International License, which permits use, sharing, adaptation, distribution and reproduction in any medium or format, as long as you give appropriate credit to the original author(s) and the source, provide a link to the Creative Commons license, and indicate if changes were made. The images or other third party material in this article are included in the article's Creative Commons license, unless indicated otherwise in a credit line to the material. If material is not included in the article's Creative Commons license and your intended use is not permitted by statutory regulation or exceeds the permitted use, you will need to obtain permission directly from the copyright holder. To view a copy of this license, visit http://creativecommons. org/licenses/by/4.0/.
\end{abstract}

(c) The Author(s) 2021 